\title{
Histopathological Evaluation of Postmenopausal Bleeding
}

\author{
Dr Pragati J Karmarkar, Dr Anne Wilkinson, Dr Mayuri Rathod \\ Department of Pathology, NKP Salve Institute of Medical Sciences, Nagpur.
}

\begin{abstract}
Post menopausal bleeding is generally regarded as an ominous and serious alarm of genital pathologies. The term "post menopausal bleeding" generally implies bleeding from the uterus and it is essentially the only bleeding of importance at the postmenopausal age. However in the practical sense the term also includes some instances of bleeding from the vagina, urethra or vulva, in which case a uterine source is held suspect until excluded. Being a symptom of varied etiologies and its strong association with malignancy, it should not be taken lightly. During the present hospital based cross sectional study, we aimed to find out the different histomorphological patterns of the endometrium and cervix, to assess the rate of different benign, premalignant and malignant conditions as a cause of postmenopausal bleeding.

250 specimens were selected. The material for the study was collected from the endometrial curettings, cervical biopsies and hysterectomy specimens sent for histopathological examination. Benign conditions were seen in $206(82.4 \%)$ cases which included atrophic endometrium, proliferative endometrium, secretory endometrium, endometrial polyp, leiomyoma, tuberculous endometritis and simple cystic hyperplasia cases. Premalignant conditions such as hyperplasia with atypia were seen in 18 (7.2\%) cases. Endometrial adenocarcinoma, cervical squamous cell carcinoma and Mixed Mullerian tumor [MMT] were the malignant condition seen in 26 $(10.4 \%)$ cases.
\end{abstract}

Key Words: Postmenopausal bleeding, histopathology

\section{Introduction}

Menopause is a physiological event occurring in women at about the age of 50. It signals the end of the reproductive years and is associated with signs of estrogen deficiency, and has a considerable impact on women's health related quality of life. Menopause is derived from the Greek word meno (month) and pause to stop. ${ }^{[1]}$ Post menopausal bleeding is generally regarded as an ominous and serious alarm of genital pathologies. It may be heavy bleeding, spotting or just a normal menstruation. Post menopausal bleeding (PMB) represents approximately $5 \%$ of all gynaecological visits. ${ }^{[2]}$

Post menopausal bleeding constitutes $73 \%$ of all gynaecological disorders in older women. According to the Indian cancer registry, there is an increasing trend for corpus uteri malignancies in the past 2 decades. ${ }^{[3]}$ The average age of menopause in Asian women is 46 years. ${ }^{[4]}$ In this era, trends in life expectancy show that women are living longer and many will experience the postmenopausal phase. Genital tract bleeding is an alarming symptom in this age group. The dictum is "postmenopausal bleeding indicates malignancy until proved otherwise". However they have a right to live a long life in good health, rather than one of pain and misery due to malignancy.

The current study was carried out to evaluate various causes of postmenopausal bleeding based on histopathology, and the percentage of various benign, premalignant and malignant endometrial and cervical lesions in post menopausal bleeding.

\section{Materials And Methods}

The present study of endometrial and cervical pathology in postmenopausal bleeding was conducted in the department of Pathology, after Institute Ethical Committee clearance.

It was a hospital based cross sectional study. The material for the study was collected from the endometrial, cervical biopsies and hysterectomy specimens sent for histopathological examination to the department of Pathology, from clinically diagnosed cases of postmenopausal bleeding. They gave a history of postmenopausal bleeding varying from spotting per vagina, brownish discharge, scanty flow and moderate to profuse bleeding, appearing six months or more after menopause.

Exclusion criteria were premature menopause whether surgical or natural, age less than 40 years and patients on hormone replacement therapy. Clinical details of the patients were obtained. The endometrial curettage and cervical biopsy material was immediately fixed in $10 \%$ fresh formalin. In the case of hysterectomy specimens, sections were taken from all the representative areas. The tissue pieces were processed routinely and were stained with hematoxylin and eosin. The histological findings were noted. 
III. Results

Table no. 1: Distribution of study subjects according to age group $(\mathrm{n}=250)$

\begin{tabular}{|c|c|c|}
\hline Age (years) & No. of study subjects & Percentage (\%) \\
\hline $41-45$ & 17 & 31.60 \\
\hline $46-50$ & 79 & 28.00 \\
\hline $51-55$ & 70 & 20.80 \\
\hline $56-60$ & 52 & 9.60 \\
\hline $61-65$ & 24 & 3.20 \\
\hline $66-70$ & 08 & $100 \%$ \\
\hline Total & 250 & \\
\hline
\end{tabular}

Table no. 2: $\quad$ Distribution of study subjects according to histological diagnosis $(\mathrm{n}=\mathbf{2 5 0})$

\begin{tabular}{|c|c|c|c|}
\hline Sr.no. & Histology & No. of patients & Percentage (\%) \\
\hline 1. & Atrophic endometrium & 80 & 32.0 \\
\hline 2. & Endometrial hyperplasia without atypia & 53 & 21.2 \\
\hline 3. & Proliferative endometrium & 42 & 16.8 \\
\hline 4. & Secretory endometrium & 10 & 4.0 \\
\hline 5. & Endometrial hyperplasia with atypia & 18 & 7.2 \\
\hline 6. & Benign endometrial polyp & 10 & 4.0 \\
\hline 7. & Tuberculous endometritis & 01 & 0.4 \\
\hline 8. & Leiomyoma & 10 & 4.0 \\
\hline 9. & Endometrial adenocarcinoma & 09 & 3.6 \\
\hline 10. & Malignant mixed Mullerian tumor & 01 & 0.4 \\
\hline \multirow[t]{2}{*}{11.} & Cervical carcinoma & 16 & 6.4 \\
\hline & TOTAL & 250 & $100 \%$ \\
\hline
\end{tabular}

\section{Discussion}

Postmenopausal bleeding is a frequent and alarming sign that may be associated with cervical or uterine malignancy. It is a common symptom, so patients presenting with it should be worked up on priority basis for early detection and further management.

We observed that maximum number of cases $(31.60 \%)$, were in the age group of $46-50$ years and minimum number of cases $(3.20 \%)$ were in the age group of 66-70 years [Table 1]. In the present study age range was 41- 70 years while in study done by Wong SF et al, Sousa R et al, Bharani B et al, and Sheikh M et al it was 38-94, 43-82, 52-65, 42-84 years respectively. ${ }^{[5,6,7,8]}$ Mean age in the present study was 53.22 years while it was 47.43 to 56.5 years in other studies. ${ }^{9}$ It was also observed that as the age of our subjects increased the incidence of postmenopausal bleeding decreased, indicating an inverse relationship between age and age of postmenopausal bleeding. Gredmark T et al in his study revealed that the number of cases of PMB decline with increasing age. ${ }^{10}$ Yousaf $\mathrm{S}$ et al also stated the same. In his study, $25(69.44 \%)$ cases of PMB were between 50 and 60 years of age, while only 5 cases $(13.89 \%)$ were above 70 years of age. ${ }^{[9]}$

In our study, there were endometrial curettage, cervical biopsies and hysterectomy specimens of 250 consecutive cases which presented with complaints of postmenopausal bleeding. Benign conditions were seen in $206(82.4 \%)$ cases which included atrophic endometrium, proliferative endometrium, secretory endometrium, benign endometrial polyp, leiomyoma, tuberculous endometritis and simple cystic hyperplasia cases. Premalignant conditions such as hyperplasia with atypia seen in $18(7.2 \%)$. The malignant conditions seen were endometrial adenocarcinoma, cervical squamous cell carcinoma and Mixed Mullerian tumor in $26(10.4 \%)$ patients [Table 2].

It was observed that atrophic endometrium [Figure 1.] was the most common histological diagnosis i.e. in $80(32 \%)$ followed by various endometrial hyperplasia [Figure 2.] in 53(21.2\%). The incidence of atrophy was found to be $49.9 \%$ by Gredmark T et al , $52.1 \%$ by Lee WH et al, $64.4 \%$ by Dangal G et al and $53 \%$ by Kaur $\mathrm{M}$ et al. They all reported endometrial atrophy as the commonest finding in patients with postmenopausal bleeding which is consistent with the present study. ${ }^{[10,11,12]}$ Philip $\mathrm{H}$ et al found atrophic endometrium $(13.3 \%)$ as the third most common cause after proliferative endometrium. ${ }^{[13]}$ Meyer et al postulated sclerotic degeneration of endometrial vessels as a cause of bleeding in atrophic endometrium. Hourihan et al stated anatomical vascular variations or local abnormal haemostatic mechanisms in the uterus as a cause of bleeding from atrophic endometrium.

Simple endometrial hyperplasias [ Figure 2.] were observed in $21.2 \%$ and it was the second most common finding next to atrophic endometrium. In other studies it ranged from $13.46 \%$ to $26.6 \%{ }^{[14,15]}$ Endometrial hyperplasia is a pathological condition of the endometrium which carries both clinical and pathological significance. It is one of the most important predisposing factors for the development of endometrial carcinoma. This risk is especially seen in atypical endometrial hyperplasia which carries the risk of 
associated endometrial carcinoma more than endometrial hyperplasia without atypia. In our study, atypical hyperplasia was observed in $7.2 \%$. It was found to range from 1.8 to $8 \%$ in other studies. ${ }^{[7,9,10]}$

In the present study, proliferative endometrium was observed in $16.8 \%$ which is comparable to the study of Phillip $\mathrm{H}$ et al who found $20 \%$. It was observed to range from $4.2 \%$ to $25.92 \%$ in other studies. ${ }^{[7,10,13,16]}$ Choo Y C et al established that stimulation of the postmenopausal endometrium can occur as a result of the conversion of adrenal androstanedione by peripheral fatty tissue to estrogen which can lead to proliferative endometrium. It is probable that a fluctuating low level of estrogen can result in proliferative endometrium that bleeds. ${ }^{[17]}$

We reported one rare case $(0.4 \%)$ of endometrial tuberculosis. Sousa $\mathrm{R}$ et al reported endometrial tuberculosis in $1.4 \% .{ }^{[18]}$

Endometrial adenocarcinoma which is the most important and threatened cause of postmenopausal bleeding, was found in $3.64 \%$ in the present study, while others have found it to range from $6 \%$ to $12 \%{ }^{[7,10,16]}$ Histologically there were 6 cases of endometrioid adenocarcinoma, 2 villoglandular endometrioid adenocarcinomas, 1 ciliated endometrioid adenocarcinoma and 1 case of malignant mixed mullerian tumor.

Squamous cell carcinoma of the cervix was responsible for $6.4 \%$ cases of PMB in our study, while it is reported to range from $8.8 \%$ to $39.6 \%$ in other studies. ${ }^{[19]}$ Hence cervical cancer was twice as common as endometrial cancer in our study of women with postmenopausal bleeding. The results support the fact that the diagnostic focus in post menopausal bleeding in our country, should also focus on excluding cervical pathology. $[20]$

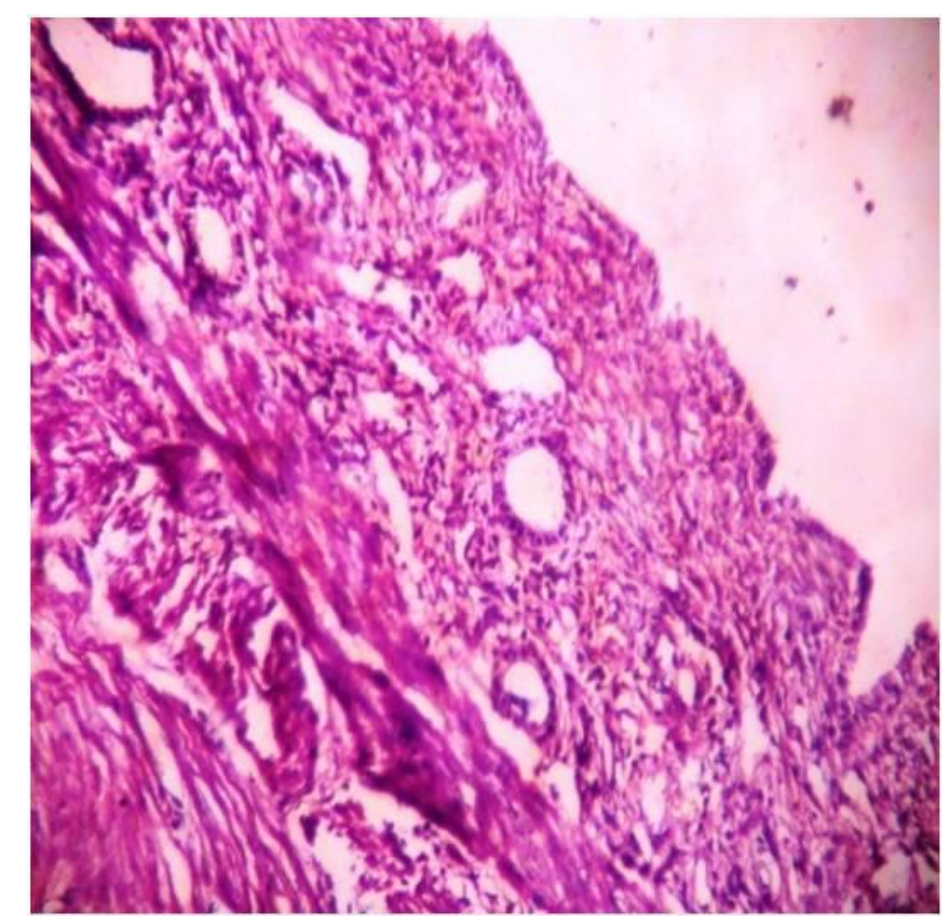

Figure 1: Atrophic endometrium with sparse, atrophic glands lined by flattened epithelium ( H\&E x100) 


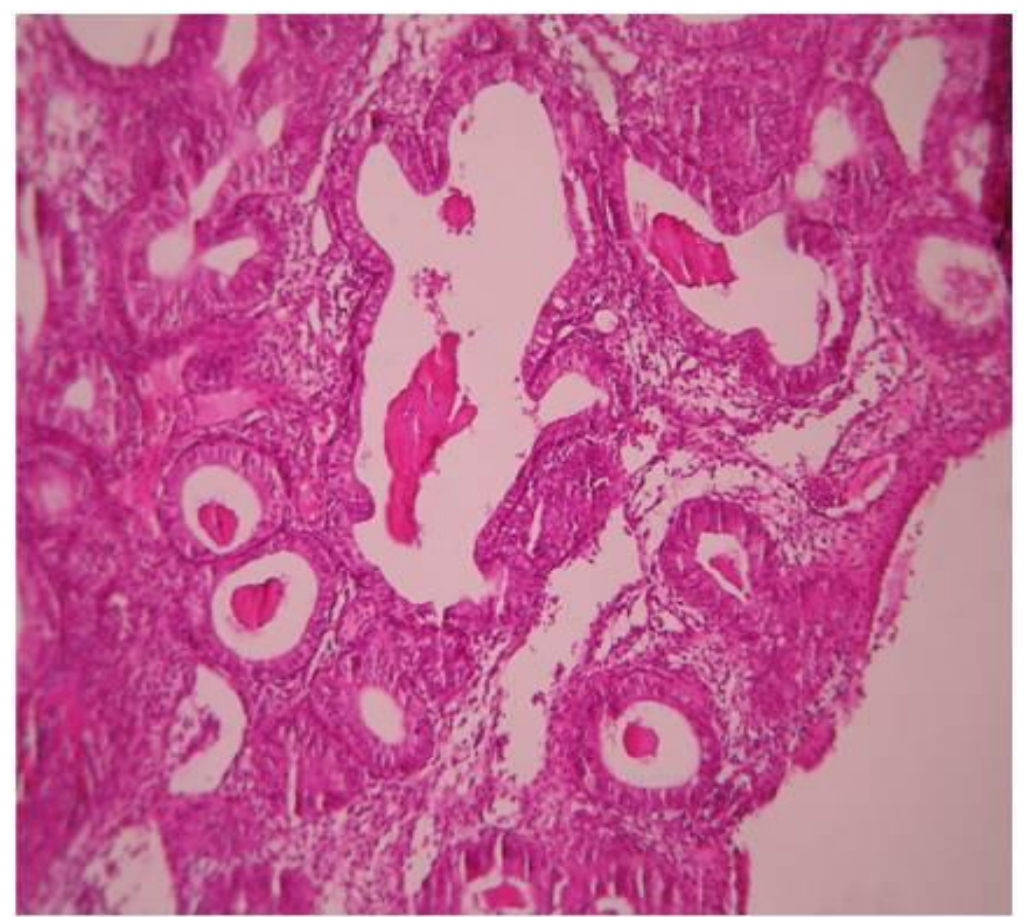

Figure 2: Simple cystic endometrial hyperplasia with glandular crowding and dilatation ( H\&E x 100 )

\section{Summary And Conclusion}

Postmenopausal bleeding is a symptom that should not be underestimated. A definitive diagnosis of PMB is made by histology. In our study benign conditions like atrophic endometrium, endometrial hyperplasia without atypia, proliferative and secretory endometrium, benign endometrial polyp, leiomyoma and tuberculous endometritis predominated in 206 patients (82.4\%). On histopathology endometrial atrophy was the commonest cause, followed by various endometrial hyperplasias with or without atypia, proliferative endometrium, cervical carcinoma.and endometrial adenocarcinoma.

Though the main aim of evaluation of cases of postmenopausal bleeding is to exclude premalignant and malignant lesions of the endometrium, majority of cases had benign causes for post menopausal bleeding. Thus postmenopausal bleeding is a symptom of varied etiologies and is not always because of malignant conditions. Therefore, careful histologic examination to find benign, premalignant and malignant lesions should be emphasized. An accurate diagnosis will not only make it much easier to counsel the patient confidently about the appropriate course of action, but also facilitate in carrying out the proper treatment plan that will benefit the patient

\section{References}

[1]. Dawood NS, Peter K, Ibrar F, Dawood A. Postmenopausal bleeding: causes and risk of genital tract malignancy. J Ayub Med Coll Abbottabad 2010; 22:117-20.

[2]. Carlos RC, Bree RL, Abrahamse PH, Fendrick AM. Cost effectiveness of saline assisted hysterosonography and office hysteroscopy in the evaluation of postmenopausal bleeding. Acad Radiol 2001; 8: 835-44.

[3]. Takkar N, Goel P, Dua D, Mohan H, Huria A, Sehgal A. Spectrum of gynaecological disorders in older Indian women: a hospitalbased study. Asian J Gerontol Geriatr 2010; 5: 69-73.

[4]. Tandulwadkar S, Deshmukh P, Lodha P, Agarwal B. Hysteroscopy in postmenopausal bleeding. J Gynec Endosc Surg 2009;1: 8993.

[5]. Wong SF, Luk KL, Wong AY, Tang LC. Findings in women with postmenopausal bleeding investigated with hysteroscopy. J Obstet Gynaecol. 2001: 21; 392-95.

[6]. Sousa R, Silvestre M, Almeida e Sousa L, Falcão F, Dias I, Silva T, De Oliveira C, Oliveira HM. Transvaginal ultrasonography and hysteroscopy in postmenopausal bleeding: a prospective study. Acta Obstet Gynecol Scand. 2001; 80: 856-62.

[7]. Bharani B, Phatak S R . Feasibility and yield of endometrial biopsy using suction curette device for evaluation of abnormal pre and postmenopausal bleeding. J Obstet Gynecol India 2008; 58:322-26.

[8]. Sheikh M, Sawhney, Khurana A, Al Yatama M. Alteration of sonographc texture of the endometrium in post-menopausal bleeding a guide to further management. Acta Obstet Gynecol Scand 2000;79:1006-10.

[9]. Yousaf S, Shaheen M. and Rana T.Frequency of Endometrial Carcinoma in Patients with Postmenopausal Bleeding. ANNALS 2010;16 290-94

[10]. Gredmark T, Sonja Kvint, Guillaume Havel, Lars Ake Maltsson. Histopathological findings in women with postmenopausal bleeding. British Journal of Obstetrics and Gynaecology 1995;102: 133-36.

[11]. Dangal G. A Study of Endometrium of Patients with Abnormal Uterine Bleeding at ChitWan Valley. Kathmandu Univ Med J 2003;1: 110-2. 
[12]. Kaur M, Singh R, Sharma M. Endovaginal Sonographic Evaluation of Postmenopausal Uterine B leeding. Journal of Clinical and Diagnostic Research 2010; 4:2175-82.

[13]. Phillip H, Dacosta VE, Fletcher HM, Kulkarni SK, Reid ME. Correlation between transvaginal ultrasound measured endometrial thickness and histopathological findings in Afro-Caribbean Jamaican women with postmenopausal bleeding. Journal of Obstetrics and Gynaecology 2004; 24: 568-72.

[14]. Veena S Naik, Jyoti D Rege, and Kusum D Jashnani. Pathology of Genital Tract in Postmenopausal Bleeding. Bombay Hospital Journal - Original/Research .www.bhj.org/journal/2005_4703_july/html/original_pathology-250.htm-17k

[15]. Ahmed JA. Clinico Pathological Evaluation of Postmenopausal Uterine bleeding in Mosul City. Tikrit Medical Journal 2007;13:7378.

[16]. Reddy Rani P, Devi JK, Papa D, Jayanthi S. Transvaginal sonography and progesterone challenge test for identifying endometrial pathology in postmenopausal women. J of Obs and Gyn of India January/February 2002;52:135-38.

[17]. Choo YC, Mak KC, Hsu C. et al. Postmenopausal uterine bleeding of non-organic cause. Obstet Gynecol 1985; 66:225 - 28.

[18]. Sousa R, Silvestre M, Almeida e Sousa L, Falcão F, Dias I, Silva T, De Oliveira C, Oliveira HM. Transvaginal ultrasonography and hysteroscopy in postmenopausal bleeding: a prospective study. Acta Obstet Gynecol Scand. 2001; 80: 856-62.

[19]. Jillani K, Khero RB, Siddiqui SMA. Prevalance of malignant disorders in 50 cases of postmenopausal bleeding. JPMA 2010; 60: $540-43$.

[20]. Epstein E, Jamei B, Lindqvist PG. High risk of cervical pathology among women with postmenopausal bleeding and endometrium $<$ or $=4.4 \mathrm{~mm}$ : long term follow-up results. Acta Obstet Gynecol Scand 2006;85:1368-74 